\title{
ARTES INDÍGENA E CONTEMPORÂNEA: ANÁLISE TEÓRICA E A VERTENTE PATAXÓ/TUPINAMBÁ
}

\author{
AUTOR: ALISSON CRUZ DE OLIVEIRA \\ CO-AUTOR/OREINTADOR: ALESSANDRA MELLO SIMOES PAIVA
}

\begin{abstract}
Resumo: Compreender a arte indígena latino-americana a partir de chaves interpretativas da história, teoria e crítica da arte, especialmente das problemáticas relacionadas ao campo da arte contemporânea e sua relação com novas epistemologias. Esta é a proposta deste projeto, que pretende ter como resultado a criação de um "site-curatorial", plataforma para a "fruição digital" das articulações entre arte indígena e contemporânea, fornecendo novos modos de olhar a arte a partir de ferramentas e recursos comunicativos criativos e experimentais. Pretende-se, assim, colaborar para uma maior visibilidade e inserção das expressões estéticas indígenas no circuito artístico contemporâneo a partir do desafio epistemológico de dar voz e visibilidade a práticas e saberes silenciados ao longo da secularização da história da arte ocidental, tendo como objetivo produzir uma ampla reflexão a respeito do tema a partir de estudos teóricos, coleta e análise de imagens e entrevistas com artistas indígenas, artistas contemporâneos e pesquisadores que tenham interface com essas problemáticas. A ideia é que o "site-curatorial" envolva noções contemporâneas de mediação que não procurem direcionar fixamente o fruidor da arte no sentido de algum cânone. Em sintonia com estratégias da nova museologia e éticas curatoriais atuais, o site procurará reconhecer que os sistemas simbólicos expostos ali estão em conflito e não podem ter seus sentidos esgotados em visões unilaterais. Assim, pretende-se contribuir para questões como: Podemos partir para reconfigurar as perspectivas teóricas a respeito da chamada arte ocidental levando-se em conta essas outras formas de fazer e pensar arte, como revelam os povos os originários atuantes na contemporaneidade? Ou: podemos reavaliar os modos de criação indígena levando-se em conta os conceitos e as poéticas da arte ocidental contemporânea? O projeto foi contemplado pela Chamada MCTIC/CNPq No 28/2018 - Universal/Faixa A.
\end{abstract}

Palavras-chave: Arte indígena, arte contemporânea, crítica de arte, teoria de arte. 